\title{
THE IMPORTANCE OF INDICATORS OF THE INITIAL PHASE OF ATHEROSCLEROSIS IN PATIENTS WITH MICROVASCULAR ANGINA
}

\author{
Marie Ščudlová, Marcela Škvařilová, Alan Bulava
}

$I^{\text {st }}$ Clinic of Internal Medicine, Palacky University, Olomouc, Czech Republic

Received: September 30, 2003; Accepted: October 10, 2003

Key words: Microvascular angina pectoris / Intima-media thickening common carotid artery / Ultrasonography determination of endothelial dysfunction

Endothelial dysfunction (ED) is generally considered to be the initial step in the progression to atherosclerosis but there is still much uncertainty about the role of the microvascular form of angina in patients with a normal coronary angiogram with regard to ED. The authors investigated the extent of endothelial perturbation and thereby whether the microvascular form of angina precedens macroscopic atherosclerosis by means of non-invasive ultrasound measurement of the intima-media thickening (IMT) in common carotid artery and flow mediated dilatation (FMD) in the brachial artery. 28 patients with stable angina with positive exercise test and ST segment depression (22 females, 6 males, average age 54 years) were compared with a control group consisting of 28 patients with no clinical signs of coronary artery disease (18 females, 10 males, average age 53 years). No significant difference in FMD\% $(7.3$ vs. 10.8, p = 0.07) was found between the groups, though specific measurements (average dilatation of the brachial artery induced by ischemic insult, peak blood flow and peak hyperemic flow) differed considerably. Also IMT did not vary significantly between the groups $(0.74$ vs. $0.65, \mathrm{p}=0.08)$. In patients with IMT $>0.8 \mathrm{~mm}$ ( 6 patients in each group) a significant decrease of FMD was found as compared with patients with normal IMT $(p<0.05)$. It was concluded that in patients with increased IMT an inverse relationship between FMD and IMT exists both in patients with microvascular angina and in the healthy control subjects whereas in the group of patients with normal IMT no ED was demonstrated. This supports the hypothesis that the microvascular form of angina is the early stage of coronary artery atherosclerosis and this escapes angiographic recognition.

\section{INTRODUCTION}

Endothelial dysfunction (ED) has been reported to be the initial step in atherosclerosis. ED represents overall functional changes characterized by vasospasm, coagulation abnormalities and increased vascular proliferation. Peripheral ED can be non-invasively determined by the flow-mediated dilatation (FMD) of the brachial artery measured with high-resolution ultrasound methods. Decrease in FMD of the peripheral artery is considered to be an early marker of atherosclerosis.

Although a positive correlation with coronary artery disease (CAD) has been shown ${ }^{1,2}$, the role of ED in patients with the microvascular form of angina (i.e. patients with a positive exercise test and normal coronary angiogram) still remains unexplained. In these patients ED measurement may help in revealing the pathogenesis of the disease since it is still unclear whether the microvascular angina represents a separate nosological entity or is just a first-step or a variant of CAD, in which angiographically recognizable atherosclerotic changes of the epicardial coronary arteries evolve due to a long-term exaggerated ED with a high prevalence of coronary artery spasm. Intima-media thickening (IMT) in the common carotid artery (CCA) is an initial marker of atherosclerosis that can be easily ultrasonographically evaluated. The goal of this study was to assess the significance of ED and IMT in a group of patients with microvascular angina.

\section{PATIENTS AND METHODS}

The study included 28 consecutive patients with microvascular angina (coronary syndrome $\mathrm{X}$ ) characterized by the presence of angina on exertion, positive exercise test with ST-segment depression and normal coronary arteriogram with no history of previous myocardial infarction and/or signs of musculo-skeletal disease. Exclusion criteria comprised congestive heart failure, renal or liver insufficiency and valvular heart disease. The control group consisted of 28 subjects with no clinical signs of heart disease.

Noninvasive determination of ED was performed according to the methods described by Celermayer et $\mathrm{al}^{3}$. Brachial artery diameter and flow velocity were measured using a 7.5 MHz linear ultrasound probe (Toshiba-Power Vision). Measurement was provided manually by caliper with accuracy $0,01 \mathrm{~mm}$. Increased flow was induced by inflation of a pneumatic tourniquet placed around the right forearm to a pressure of 40 torr above systolic pressure for 3 minutes followed by release. Scans of the brachial artery were obtained $10 \mathrm{~cm}$ proximal to the bifurcation. 
The lumen diameter of the brachial artery was measured in a longitudinal section in B-mode imaging from anterior A-line to posterior $\mathrm{B}$-line $(\mathrm{A} / \mathrm{B}$ line $=$ intima/lumen interface) at end diastole. Measurements were done at rest and during reactive hyperemia (endothelium-dependent vasodilatation) 45-60 seconds after the deflation of the tourniquet. Three measurements were performed and an average value was thereafter used for further calculations. The FMD was expressed as the changes in end-diastolic diameter of the brachial artery during reactive hyperemia compared with the baseline measurement. Previous studies confirmed that this technique was both reproducible and reliable ${ }^{4,5,6}$. FMD\% value indicates the change in diameter of the dilated vessel. Baseline blood flow (rest flow) was estimated by multiplying the velocity time integral of the Doppler flow signal and the vessel cross-sectional area of the brachial artery $\left(\pi \cdot r^{2}\right)$. Reactive hyperemic flow was calculated as the maximum flow recorded during the first 15 seconds after release of the forearm occlusion divided by the flow during resting.

IMT in the CCA was measured in B-mode using a 7.5 MHz linear ultrasound probe. Both CCAs were examined $1 \mathrm{~cm}$ below the bifurcation. Six measurements (three on each side) were averaged and the value was thereafter used for further calculations. Normal range of IMT for people bellow sixty is under $0.8 \mathrm{~mm}$. This technique has been previously described ${ }^{7-9}$ and is considered reliable in validation of the initial stages of atherosclerosis.

Coronary angiograms were performed using a modified Seldinger technique from the right common femoral artery. Main left and right coronary arteries were imaged in five and three basic projections, respectively. Additional projections were performed where necessary. Smooth vessel contour with good blood flow to the periphery was considered a normal finding.

Statistical analyze were performed using t-test, MannWhitney $U$ test and $\chi^{2}$-test where appropriate. A $p<0.05$ was considered statistically significant.

\section{RESULTS}

28 patients of average age 54 years (range 37-68) matching the inclusion and exclusion criteria were examined over the years 2001-2002. The control group consisted of 28 patients aged 53 years (range 22-77). Overall characteristics of patients are listed in Tab. 1.

Statistically significant differences of diameter of the brachial artery were found in the microvascular angina group compared to the controls ( 4.25 vs. $4.67, \mathrm{p}=0.01$ ). Also hyperemic flow following an ischemic insult was significantly different between the groups (371 vs. 558 , $\mathrm{p}<0.001)$. Despite these partial differences, overall FMD\% did not reach statistically significant differences between the patients with microvascular angina and the healthy subjects $(7.3$ vs. $10.8, p=0.07)$. All measurements are listed in Tab. 2.
IMT in CCA did not significantly differ between the groups, though the patients with microvascular angina tended to have greater IMT than controls by $0.1 \mathrm{~mm}$ on average (Fig. 1). There was an identical number of patients with IMT $>0.8 \mathrm{~mm}$ in both groups (6/28). FMD \% values significantly differed in the subgroup of patients with IMT >0.8 mm: in microvascular angina patients FMD\% was 4.11 compared with 6.95 FMD\% in the control group $(\mathrm{p}<0.03)$ - Fig. 2. Individuals with IMT $>0.8 \mathrm{~mm}$ also had significantly decreased endothelial function compared to normals with $\mathrm{IMT} \leq 0.8 \mathrm{~mm}$ - FMD\% 0.41 vs 0.98 ( $p<0.03)$.

Table 1. Characteristic of the study group and controls.

\begin{tabular}{|l|c|c|}
\hline & patients & controls \\
\hline $\mathrm{n}$ & 28 & 28 \\
\hline age $(\mathrm{y})$ mean & 54.9 & 53.0 \\
\hline sex (M/F) & $6 / 22$ & $10 / 18$ \\
\hline BMI > 25 & 18 & 11 \\
\hline current smoker & 5 & 4 \\
\hline hypertension & 10 & 2 \\
\hline hyperlipidemia & 6 & 0 \\
\hline ACE-inhibitors & 8 & 2 \\
\hline statins & 6 & 0 \\
\hline
\end{tabular}

Table 2. Results of ultrasound measurements IMT and flow parameters.

\begin{tabular}{|l|c|c|c|}
\hline & patients & controls & p values \\
\hline IMT (mm) & $0.746 \pm 0.16$ & $0.659 \pm 0.2$ & 0.08 \\
\hline $\begin{array}{l}\text { rest flow } \\
(\mathrm{ml} / \mathrm{min})\end{array}$ & $185 \pm 80$ & $208 \pm 74$ & 0.26 \\
\hline $\begin{array}{l}\text { hyperemic } \\
\text { flow } \\
(\mathrm{ml} / \mathrm{min})\end{array}$ & $371 \pm 162$ & $558 \pm 235$ & $0.001^{* *}$ \\
\hline $\begin{array}{l}\text { diameter } \\
\text { AB after } \\
\text { ischemia } \\
(\mathrm{mm})\end{array}$ & $4.259 \pm 0.55$ & $4.678 \pm 0.64$ & $0.012^{*}$ \\
\hline FMD\% & $7.3 \pm 6.3$ & $10.8 \pm 7.9$ & 0.07 \\
\hline
\end{tabular}

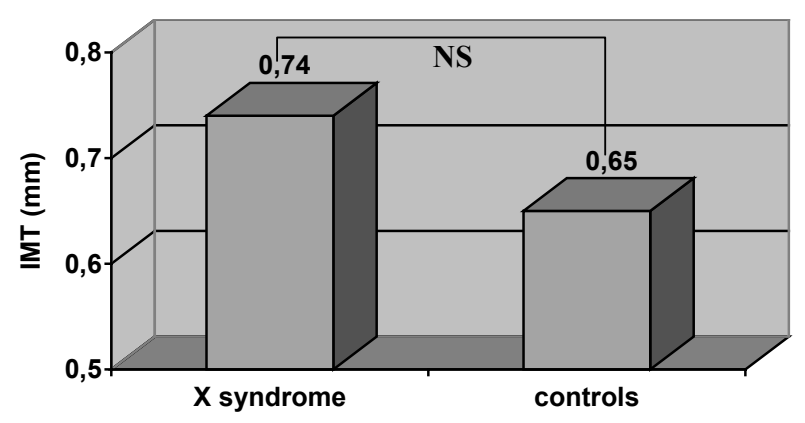

Fig. 1. IMT in subject with syndrome $X$ and controls 


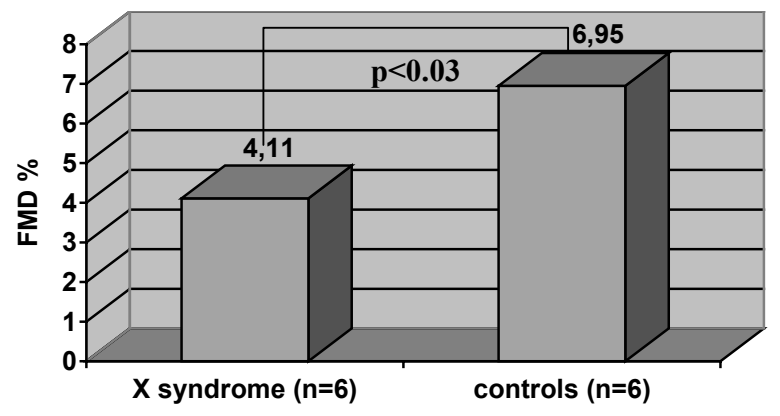

Fig. 2. FMD\% in all subject with IMT $>0.8 \mathrm{~mm}$

\section{DISCUSSION}

Although etiopathogenetical mechanisms of microvascular angina have not been fully elucidated, general agreement prevails that enhanced coronary artery spasticity may be explained by endothelial dysfunction. Disturbance of vascular dilatation due to low NO synthesis in the vascular wall leads to predominance of vasoconstriction which is usually associated with increased platelet adhesivity and increased endothelial permeability for lipoproteins and white blood cells leading to connective tissue proliferation.

This study focused on endothelial perturbation in microvascular angina and the relationship of endothelial dysfunction to early atherosclerosis. Important endothelial perturbation with pronounced decrease in FMD has been already described in coronary artery disease ${ }^{1}$. A number of studies have shown a correlation of FMD decrease with severity of coronary artery stenosis ${ }^{2}$ but others have failed to confirm this relation ${ }^{10}$. Other authors have found a negative correlation between FMD and IMT in coronary artery disease ${ }^{11}$. The results of studies focused on FMD in microvascular angina are inconsistent. Some have proved impaired endothelial function in peripheral arteries ${ }^{12-14}$, some have not ${ }^{15,16}$. Our own results likewise have not produced clear evidence that a spastic disorder of the coronary microcirculation is accompanied by simultaneous perturbation of endothelial-dependent vasodilatation in peripheral circulation which could be thus referred to as a systemic vasomotoric disease. This discrepancy may originate from different patients selection.

While in the cohort of Motoyama et $\mathrm{al}^{14}$ and ours there were only patients with ST segment depressions during exercise test, Ito et $\mathrm{al}^{15}$ and Botker et $\mathrm{al}^{16}$ comprised patients with ST segment elevations. Nevertheless, Ito found also in 7 patients with ST segment depressions and angiographically documented coronary spasms, relatively normal endothelial function.

Another important limitation is the relatively small number of patients in the aforementioned studies on microvascular angina. Even in our larger group of patients the presence of ED was not unambiguously confirmed. A question remains, as to what extent previous medication may have influence the present results. One fifth of the patients were treated by ACE inhibitors or statins for concomitant hypertension or hyperlipoproteinemia, respectively, and both drugs are known to influence ED. Angiotensin converting enzyme acts on the rennin-angiotensin axis, decreasing the production of angiotensin II and diminishes degradation of bradykinin, which has potent vasodilatatory effect. Statins are known for their pleiotropic effects. They increase t-PA activity and the production of NO-synthase, decrease production of endothelin-synthase, platelet reactivity and expression of adhesive molecules. The question remains the influence of interruption of medication for two days of results of measurements.

The predictive importance of IMT in CCA for recognition of the early stage of atherosclerosis has been proven in many clinical studies. IMT consists of both intimal atherosclerotic process and medial hypertrophy. Since IMT is increased in patients with familial hypercholesterolemia ${ }^{17}$ and diminished with cholesterollowering drugs ${ }^{18}$, it significantly reflects the early stage of atherosclerosis. In patients with microvascular agina, no significant difference of IMT against healthy controls was found in this study. This is in concordance with the previous study of Lekakise et al ${ }^{12}$. In his group of patients he found no significant discriminative IMT value between 11 women with vasospastic angina with normal coronary angiograms and healthy controls. The only significant difference was between patients with CAD and normal individuals. Nevertheless, patients in our study with IMT above the normal value showed deteriorating peripheral endothelial function, which in patients with microvascular angina manifested itself as a more significant decrease FMD compared to controls.

Some risk factors of atherosclerosis as smoking ${ }^{19}$, hyperlipoproteinemia ${ }^{20}$ or hyperhomocysteinemia ${ }^{21}$ or mental stress ${ }^{22}$ inevitably worsen endothelial function and the association between ED and increased IMT has been proven $^{23}$.

Although localized or diffuse spasm of the coronary arteries are typical in the etiology of microvascular angina, it is not currently clear whether this variant of angina is a preclinical stage of CAD, or whether it is merely a coronary manifestation of systemic vasomotoric disorder with tendency to vasoconstriction. In some patients combined vasomotoric disorders have been described, i.e. vasoconstriction in the cerebral arteries with the evolution of migraine or in the digital arteries with the manifestation of Raynaud's phenomenon ${ }^{15}$. Besides ED, neural dysbalance or adenosine receptor disorder should be taken into account. Intravascular ultrasound (IVUS) of the coronary arteries that can precisely describe the morphology of the arterial wall seems to be a promising method answering this question.

On the basis of the results of this study we conclude that spastic phenomen in the coronary artery circulation are not necessarily accompanied by endothelial dysfunction. Ultrasound measurement of the flow mediated dilatation or intima-media thickening should not be therefore routinely used to support the diagnosis of microvascular angina. 


\section{REFERENCES}

1. Schroeder S, Enderle MD, Ossen R, Meisner C, Baumbach A, Pfohl M, Herdeg C, Oberhoff M, Haering HU, Karsch KR. (1999) Noninvasive determination of endothelium-mediated vasodilatation as a screening test for coronary artery disease: Pilot study to assess the predictive value in comparison with angina pectoris, exercise electrocardiography, and myocardial perfusion imaging. Amer Heart J. 138, 731-739.

2. Neunteufl T, Katzenschlager R, Hassan A, Klaar U, Schwarzacher S, Glogar D, Bauer P, Weidinger F. (1997) systemic endothelial dysfunction isrelated to the extent severity of coronary artery disease. Atherosclerosis 129, 111-118.

3. Celermajer DS, Sorensen KE, Gooch VM, Spiegehalter DJ, Miller OI, Sullivan ID, Lloyd JK, Deanfield JE. (1992) Non-invasive detection of endothelial dysfunction in children and adults at risk of atherosclerosis. Lancet 340, 1111-1115.

4. Ito K, Akita H, Kanazawa K, Yamada S, Terashima M, Matsuda Y, Yokoyama M. (1998) Comparison of effect of ascorbic acid on endothelium-dependent vasodila-Tation in patients with chronic congestive heart failure secondary to idiopathic dilated Cardiomyopathy versus patients with effort angina pectoris secondary to coronary artery disease. Amer J Cardiol. 82, 762-767.

5. Sorensen KE, Celermayer DS, Spiegelhalter DJ, Georgakopoulos D, Robinson J, Thomas O, Deanfield JE. (1995) Non-invasive measurement of human endothelium dependent arterial responses: accuracy and reproducibility. Br Heart J, 74, 247-253.

6. Hashimoto M, Akishita M, Eto M, Ishikawa M, Kozaki K, Toba K, Sagara Y, Taketani Y, Orimo H, Ouchi Y. (1995) Modulation of endothelium-dependent flow-mediated dilatation of the brachial artery by sex and menstrual cycle. Circulation 92, 3431-3435.

7. Salonen R, Salonen JT. (1991) determinants of carotid intima-media thickness: a population-based ultrasonography study in eastern Finnish men. J Intern Med 229, 225-231.

8. Salonen JT, Salonen R. (1993) Ultrasound B-mode imaging in observational studies of atherosclerotic progression. Circulation 87 (suppl II) II-56 - II-65.

9. Wendelhag I, Gustavsson T, Suurkula M, Berglund G, Wikstrand J. (1991) Ultrasound measurement of wall thickness in the carotid artery: fundamental principles and description of a computerized analysing systém. Clin Physiol 11, 565-577.

10. Schroeder S, Enderle MD, Meisner C, Baumbach A, Herdeg C, Oberhoff M, Ossen R, Pfohl M, Karsch KR. (1999) The ultrasonic measurement of the endothelial function of the brachial atrery in suspected coronary heart disease. Deutsch Med Wochenschrift 124, 886-890.

11. Enderle MD, Schroeder S, Ossen R, Meisner C, Baumbach A, Haering HU, Karsch KR, Pfohl M. (1998) Comparison of peripheral endothelial dysfunction and intimal media thickness in patients with suspected coronary artery disease. Heart 80 , $349-354$.
12. Lekakis JP, Papamichael CM, Vemmos CN, Voutsas AA, Stamatelopoulos SF, Moulopoulos SD. (1998) Peripheral vascular endothelial dysfunction in patients with angina pectoris and normal coronary arteriograms. J Amer Coll Cardiol 31, 541-546.

13. Bellamy MF, Goodfellow J, Tweddel AC, Dunstan FD, Lewis MJ, Henderson AH. (1998). Syndrome $\mathrm{X}$ and endothelial dysfunction. Cardiovasc Res 40, 410-417.

14. Motoyama T, Kawano H, Kugiyama K, Okumura K, Ohgushi M, Yoshimura M, Hirashima O, Yasue H. (1997) Flow-mediated, endothelium dependent dilatation of the brachial arteries is impaired in patients with coronary spastic angina. Amer Heart J 133, 263-267.

15. Ito K, Akita H, Kanazawa K, Yamada S, Shiga N, Terashima M, Matsuda Y, Takai E, Iwai C, Takaoka H, Yokoyama M. (1999) Systemic andothelial function is preserved in men with both active and inactive variant angina pectoris. Amer J Cardiol 84, 1347-349.

16. Botker HE, Sonne HS, Sorensen KE. (1996) Frequency of systemic microvascular dysfunction in syndrome $\mathrm{X}$ and in variant angina. (1996) Amer J Cardiol 78, 182-186.

17. Wendelhag I, Wiklund O, Wikstrand J. (1992) Arterial wall thickness in familial Hypercholesterolemia: ultrasound measurement of intima-media thickness in the common carotid artery. Arterioscler Thromb 12, 70-77.

18. Hodis HN, Mack WJ, LaBree L, Selzer RH, Liu C, Liu C, Alaupovic P, Kwong FH, Azen SP. (1996) reduction in carotid arterial wall thickness using lovastatin and dietary therapy: a randomized controlled clinical trial. Ann Intern Med 124, 548-556.

19. Celermajer DS, Sorensen KE, Georakopoulos D, Bull C, Thomas O, Robinson J, Deanfield JE. (1993) Cigarette smoking is associated with dose-related and potentially reversible impairment of endothelium-dependent dilation in healthy young adults. Circulation $88,2149-2155$

20. Sorensen KE, Celermajer DS, Georgakopoulos D, Hatcher G, Betteridge DJ, Deanfield JE. (1994) Impairment of endotheliumdependent dilation is an early event in children with familial hypercholesterolemia and is related to the lipoprotein (a) level. J Clin Invest 93, 50-55.

21. Tawakol A, Omland T, Gerhard M. (1997). Hyperhomocysteinemia is associated with impaired endothelium-deopendent vasodilation in humans. Circulation 95, 1119-1121.

22. Ghiadoni L, Donald AE, Cropley M, Mullen MJ, Oakley G, Taylor M, O'Connor G, Betteridge J, Klein N, Steptoe A, Deanfield JE. (2000) Mental stress induces transient endothelial dysfunction in humans. Circulation 102, 2473-2478.

23. Hashimoto M, Eto M, Akishita M, Kozaki K, Jako J, Iijima K, Kim S, Toba K, Yoshizumi M, Ouchi Y. (1999) Correlation between flow-mediated vasodilatation of the brachial artery and intima-media thickness in the carotid artery in men. Arterioscler Thromb Vasc Biol 19, 2795-2800. 